\title{
The European Stability Pact and Feedback Policy Effects
}

\author{
Jérôme Creel \\ Observatoire Françis des Conjonctures Economiques
}

\begin{abstract}
With a two-country dynamic model in a monetary union with wealth private behaviors, we study the implications of public debt on monetary and fiscal policies. The model used has Keynesian features in the short run and Wicksellian ones in the long run. We analyse the effects of asymmetric fiscal policies in Euroland and show that such a situation creates two feedback effects which reduce the efficiency of economic policies. First, because of the inability of one government to implement an expansionary fiscal policy, the other government has to substitute for it to reach economic targets. Second, the ECB's involvement in macroeconomic stabilisation will be exacerbated. The more substantial these effects, the more coordination is needed between European governments and the ECB.
\end{abstract}

- JEL Classifications: E17, E63, H63

- Key Words: EMU, Stability and Growth Pact, Monetary Policy, Fiscal Policy, Public Debt.

\section{Introduction: the European Institutional Framework}

The advent of the European monetary union, now called Euroland, accelerated following the Maastricht treaty (December 1991). Most institutional dispositions for the EMU in fact ensue from this treaty and have then been completed by the Stability and Growth Pact (Amsterdam Council, June 1997, clarified during the Luxemburg Council, December 1997). These dispositions are being applied since

*Corresponding address: OFCE, Research Department, 69, Quai d'Orsay, 75340 Paris cedex 07, France. Tel: +33-1-44-18-54-56, Fax: +33-1-44-18-54-78, E-mail : creel@ofce.sciences-po.fr

(C2002-Center for International Economics, Sejong Institution, All Rights Reserved. 
the $1^{\text {st }}$ January of 1999.

Eleven countries from the European Union (EU) first joined the Euroland; they were caught up by Greece on the $1^{\text {st }}$ January of 2001. At first sight, the size of this new monetary zone, which includes some of the bigger ones (except the UK) and many small ones (Ireland, Spain, Portugal...), may incorporate much heterogeneity from one country to the other, despite the urge for a high degree of prior nominal economic convergence as a precondition for the entry into the Euroland ${ }^{1}$. Competitiveness, the degree of openness, the industrial and trade structures, even the unemployment rate, are among these notorious heterogeneous components. They may therefore necessitate the implementation of differentiated domestic policies.

Monetary policy in the Euroland is however "unique" and assigned to a nominal target. The European common monetary policy is implemented by the European System of Central Banks (ESCB), made up of the very centralised European Central Bank (ECB) and domestic central banks of the Euroland. Its main objective is "to ensure price stability" (Maastricht tr., art. 105). The ECB and domestic central banks are independent from national governments as well as from the European Commission (EC) ${ }^{2}$ (Maastricht tr., art. 107). It follows that central banks cannot monetise public debt, and buy or sell Treasury bills or bonds (Maastricht tr., art. 104).

In contrast, fiscal policies are still in the hands of national governments - fiscal federalism or coinsurance ${ }^{3}$ have not yet been improved - and their sole instrument for coordination is comprised into the Broad Economic Policy Guidelines (BEPG) which only consist in the preparation by the $\mathrm{EC}$ of non binding recommendations on economic policy and economic reforms, adopted by the ECOFIN Council ${ }^{4}$.

Coordination of fiscal policies among $E U$ countries has been reinforced by the creation of the Eurogroup (ECOFIN Council, October 1997). This institution, nonetheless, has no binding power: it has to improve the exchange of informations between countries regarding their economic overall situation; it has to monitor these situations and their incidence on public finances; finally, it has to control for the evolution of labor market reforms. This informal-type of coordination seems

"The rationale for "convergence criteria" is dealt with, for instance, in Gros \& Thygesen (1992).

${ }^{2}$ The Commission is independent from the member states of the EU; its prerogatives are to represent the common interest of $E U$ countries, to make propositions to the Council (which embodies the representation of national governments), and to implement the decisions which are taken by the Council. ${ }^{3} \mathrm{Cf}$. Eichengreen (1993) for a presentation of the main arguments on this topic.

${ }^{4}$ i.e. regular meetings of the Ministries of Finance of the $E U$ countries. 
more close to the notion of "cooperation" than to what textbooks usually call the "coordination of macroeconomic policies between two (or more) countries". The single European binding coordination commitment is a very restrictive one: the "Stability and Growth Pact" (SGP) sets discretionary limits on fiscal rooms for maneuver (public deficits must be inferior to $3 \%$ of GDP) to which are associated sanctions to governments which would have "excessive public deficits". Although sanctions and the SGP may not appear credible (see Artis \& Winkler, 1998), the Maastricht and Amsterdam treaties neither resolved the problem regarding economic policies coordination in the $E U$, nor organised fiscal federalism. The socalled "coordination" is asymmetric: in order to prevent any drift in public finances, any temptation or risk to monetise public debts, any loss of credibility by the independent Central bank ${ }^{6}$, fiscal policy is compelled to the absolute norm of a public deficit inferior to $3 \%$ of $G D P$, whereas there is no limitation on public surpluses although they may depress economic activity in the whole $E U$.

The rest of the paper proceeds as follow. In the next section, we discuss some specific problems with the implementation of the $S G P$, notably the fact that it introduces an asymmetry in the fiscal framework between countries which, on the one hand, benefit from sound public finances; and, on the other hand, those which have already high deficits (though inferior to the $3 \%$ of GDP limit) or high public debts. We mention some major papers related to the more general topic of coordination of economic policies in section 3 , and stress the prominent differences we introduce in the present paper. Then, we outline our analytical framework, mentioning its most notable features. Section 5 provides an evaluation of the consequences of a demand shock in the $E U$, whether symmetric or asymmetric. The shock in the economy (or economies) is supposed to be permanent. Nash equilibria between the three autonomous policymakers are computed and are then compared with coordinated equilibria, where the latter are computed following the Nash-bargaining procedure. Last section brings out some conclusions.

\section{Some Problems with the Stability and Growth Pact}

Two macroeconomic implications of the Pact are already clear. On the one

\footnotetext{
5"The joint design of macroeconomic policies to improve the economic situation in the two (or more) countries" (Blanchard, 2000).

${ }^{6} \mathrm{Cf}$. Eichengreen \& Wyplosz (1998).
} 
hand, it will be more difficult or maybe impossible for certain European governments to provide an optimal regulation for economic fluctuations. In the present situation, though the situation of public finances is less dramatic than in the early nineties and though the Maastricht's norm on public debt has been wiped out as regards the entry of some countries in the Euroland, it is straightforward to show that the public finances in these countries (Belgium, Italy) is carefully supervised by the Commission, Member States or the ECB before it sets the interest rate ${ }^{7}$. Any deviation in the way to fiscal contraction will be penalised by financial markets operators (according to the discrimination principle developed by Buiter \& Kletzer, 1991), households (Ricardian equivalence along Barro's, 1974, or Giavazzi \& Pagano's, 1990, analyses), the Commission or the ECB (in order to preserve its credibility). In this sense, fiscal policies in these countries will be pro-cyclical.

Let us be clear on this point. Despite the SGP, it is not at all sure that countries in the Euroland will be fettered by its provisions after a supply or demand shock. This will be all the more true if they have already recovered fiscal room for maneuver. However, some countries will surely have to spare any additional increase in their public debt over GDP ratio in the following years. These countries will have to pursue balanced fiscal policies in the best case, or to keep large primary surpluses, in the worst ${ }^{8}$.

On the other hand, the SGP implies that the ECB will strategically dominate governments in the short run: it will set its policy in line with its goal of price stability and if fiscal policies are judged too expansionary, it will further increase the nominal European interest rate. Governments will have to choose between reducing their spending, i.e. a domination by the $E C B$; increasing them to compensate the restrictive impact of monetary policy (as in Alesina \& Tabellini, 1987); last, trying to co-operate with the $E C B$. Based on the circumstances during the convergence stage, governments might well choose the first solution.

Two other consequences of the Pact have been neglected so far, as far as we

${ }^{7}$ Quoted in the FT, June 5 2001: “The performance of Silvio Berlusconi's centre-right government will be watched closely by its European Union partners over the next few months. No aspect will come under closer scrutiny than its management of Italy's public finances. (...) The level of Italy's sovereign debt is still nearly double that permitted by the Maastricht treaty (...). Many Europeans are, therefore, anxiously waiting to see whether Mr Berlusconi (...) can maintain the same level of fiscal rigour (...) as the centre-left did in years gone by." (Italy Survey, p.II)

${ }^{8}$ Still the Italian case: "Country-specific recommendations in the 2000 BEPG: (...) Achieve a primary surplus of minimum 5.0\% of GDP in 2000 and 2001, namely through a tight control of current primary expenditure." (European Economy, 2001, p.95) No comment...except the degree of implementation for 2000: completed. 
know. First, the inability of a government to implement a fiscal policy after a shock has occurred may impinge largely on its $E U$ partners: these governments should be compelled to use their own fiscal expenditures to offset the shock. This situation resembles that of the free rider. If expansionary fiscal policies can produce favourable effects which spill over among $E U$ 's countries, they also have costs to the country which has increased the deficit: implementation costs, sunk costs and, last but not least, financial costs through the interest charges which impede the future capacities of governments to implement fiscal policies.

Second, the $E C B$ will also suffer from the constraints of the Pact. It will have to substitute for the absence of fiscal policy in a country under the rule of the Pact. Hughes Hallett \& Vines (1993), or Jensen (1997), have already mentioned this type of effect and have related it to the ability (or inability) of the central bank alone to remove the adverse effects of an asymmetric shock. We add another dimension to this effect: the ability (or inability) of the central bank to remove the effects of this peculiar shock on public finances. In the long run, if one opposes to the Barro-Ricardian equivalence between tax and public borrowing a theory of wealth effects linked to public debt holding by households, along the lines of Patinkin (1965) and Blanchard (1985), the central bank will have to adjust households' private wealth plans to actual public debt and net foreign assets levels. If, for example, public debt increases in relation to GDP after a negative private demand shock, the central bank will have to choose between reducing the interest rate to curb debt's accumulation or increasing it to make private wealth grow faster. Depending on its reaction in the long run, the central bank will be more or less fettered in its policy choices and its ability to smooth economic fluctuations.

To illustrate these two feedback effects in the $E M U$, we use a two-country model with dynamic behaviors: private consumption depends on the accumulation of wealth; inflation depends on past inflation; and wealth depends on the accumulation of public debt and net foreign assets. We assume that one of the two countries has no fiscal room for maneuver because it has already reached the deficit ceiling of the $S G P$. Its government must strictly meet its budget constraint. We further assume that the other government and the $E C B$ implement economic policies which are the outcomes of a game, in which loss functions are minimised at each period. We not only consider uncoordinated equilibria between the two governments and the $E C B$ but also a coordinated equilibrium between the three authorities, from whom we are able to assess the possible gains from coordination after an asymmetric shock has hit the Euroland. 


\section{Previous Literature}

The policy framework differs from that found usually in two-country models dealing with the EMU. First, in our framework, countries face asymmetric strategic situations. Second, in many models ${ }^{9}$, each government follows a strict balanced-budget rule so that stability conditions are met. In our framework, it is necessary, as far as the stability of wealth accumulation is concerned, that public debt over GDP be stable in the long run, but not in the short run. Hence, fiscal policies here may well reveal macroeconomic stabilisation properties which are absent from other models.

Van Aarle \& Garretsen (2000) and van Aarle et al. (2001), among others, did also studied the implications of the EMU on the implementation of fiscal and monetary policies, with a special emphasis on structural differences among $E U$ countries and European fiscal transfers (first paper); and labor market institutions, fiscal stringency and coordination (second paper). If some of our concerns are shared with these two papers, we differ much in terms of theoretical framework. In both articles in fact, the introduction of LM-type equation representing the equilibrium on the money market makes the nominal interest rate be an exogenous variable, quite at odds with the literature on the "Taylor rule" according to which central bankers would set the interest rate in relation to deviations of the inflation rate and GDP from their targeted levels. In our model, increasing the nominal interest rate can be viewed as an incentive put forth by the central banker towards more fiscal discipline. There is thus room for potential conflicts between the central bank and the governments, a major fear in the EMU as the early $21^{\text {st }}$ century slowdown in the US feedbacks in the EU. Moreover, we are interested in the net wealth effect which is totally absent from these two papers: the debt and assets dynamics are not even mentioned.

As for the specific topic of coordination in a monetary union, we depart from two influential papers, Beetsma \& Bovenberg (1998), on the one hand; and Eichengreen \& Ghironi (1997), on the other. The former use a Barro-Gordon-type model in which loss functions, even that of the central bank, incorporates an inflation bias. The resulting coordination of fiscal policies is counter-productive: because each coordinating government tends to internalize the reactions of the other governments, they share the same behavior as governments' outside the

\footnotetext{
${ }^{9}$ See, for instance, Barrel \& Sefton (1997), Capoen \& Villa (1997), Eichengreen \& Ghironi (1997), Jensen \& Jensen (1995), van der Ploeg (1995).
} 
monetary union at the uncoordinated equilibrium. The inflation rate is thus pushed upward. We depart from this line of reasoning in that we consider that inflation is not the outcome of a game between the authorities but depends on the difference between the aggregate demand and supply on the goods market, after the different authorities have set their instruments. Our model has also Keynesian features in the short run and it is therefore at odds with the Barro-Gordon modelling. We also consider backward-looking indexation, hence some inflation persistence ${ }^{10}$, which is not suitable in the Barro-Gordon framework. As for Eichengreen \& Ghironi (1997), they assume that public finances are always balanced, so that even in their "Keynesian case", there are no Keynesian policies, in the sense that no fiscal deficits can occur after a negative shock. Moreover, Beetsma \& Bovenberg (1998) and Eichengreen \& Ghironi (1997) do not study the case of coordination of fiscal and monetary policies. The latter only take into consideration a coordination between central banks and, at the same time, a "global" fiscal coordination.

The two papers from whom we are the closest are Blake \& Weale (1998) and Leith $\&$ Wren-Lewis (2000). We share with the former the concern in the coordination of fiscal and monetary policies within a backward-looking expectations framework. The latter component enables to focus exclusively on the relationship between the governments and the central bank, without having to introduce a fourth player, namely households. With the second paper, we share the specification of aggregate consumption which includes a net wealth effect, although we drop their microfoundations, and we are able to study how the wealth effect impinges on the determination of inflation. We extend these two papers in two directions. We consider a monetary union, whereas both of them were set in a closed economy; and we introduce an asymmetry in the fiscal framework of the two countries.

\section{The Model}

In this section, we deal with the specifications of the model, with a special emphasis on the wealth effect and on the policy framework.

\footnotetext{
${ }^{10} \mathrm{Cf}$. Ghezzi (2001) for an elegant extension of the standard staggered-price setting to the case with backward-looking indexation. On empirical grounds, see Fuhrer (1997) and Gali et al. (2001). The former show that the incorporation of forward-looking components in the determinants of inflation are not significant. The latter add microfoundations, based upon the New Keynesian framework, and show that inflation is persistent but information on it is improved by the inclusion of forward-looking components. Jondeau \& Le Bihan (2001) propose additional evidence on this debate and conclude that half of present inflation is significantly explained by past inflation while the other half depends on forward-looking inflation.
} 


\section{A. Aggregate Demand and Wealth Effect}

In a recent paper, Leith \& Wren-Lewis (2000) examined the interactions between monetary and fiscal policy in a closed economy with sticky prices and non-Ricardian consumers (finitely-lived agents face a higher discount factor than the government), thus using a model with wealth private behaviors ${ }^{11}$. Although we will drop the microfounded specification of intertemporal consumption, we will retain most of Blanchard's (1985) consumption features. To do so, we introduce a planned wealth and a speed of adjustment of actual wealth towards it.

Thus, the model is dynamic and can be characterised by the wealth behavior of private agents in the economy. We study a polar case in the EMU: two countries, identical as far as private behaviors are concerned, form a monetary union ${ }^{12}$. The model has Keynesian features in the short run (output $Y$ is driven by the level of demand, prices adjust slowly to their steady state levels) but Wicksellian features in the long run: output is determined according to the real equilibrium interest rate, which depends on the effects of monetary and fiscal policies on the inflation rate. Aggregate demand is similar to that used in Mundell-Fleming models, except that we introduce a wealth effect. Aggregate supply follows a Phillips curve.

Households in both countries hold wealth which is the sum of public debt and net foreign assets. As in Leith \& Wren-Lewis (2000), we do not introduce physical capital in the analysis. Introducing it in a framework with a real wealth effect (as in the ECB Euro-area-wide model, see Fagan et al., 2001, or in Multimod, see Laxton et al., 1998) would not add much to our results insofar as we already have a non-linear effect of the real interest rate on the aggregate demand. In the Blanchard (1985) model, the aggregate consumption function $C$ was shown to be, disregarding human wealth:

$$
C_{t}=(k+\sigma) B_{t},
$$

where $k$ is a constant probability of death, $B$ is public debt and $\sigma$ is the discount rate. The real interest rate did not appear directly in consumption, nor in aggregate demand - there was also no capital in the economy - but, indirectly, it had two effects: higher interest rates reduce discounted human wealth leading to a fall in consumption, but as net financial assets increase, consumption increases also.

Had physical capital been included, the negative effect of the real interest rate

\footnotetext{
${ }^{11}$ Their microfoundations were based upon Blanchard's (1985) perpetual youth model.

${ }^{12}$ Equations in country 2 will be obtained by circular permutation; this countrys variables will be starred.
} 
on aggregate demand in the short run would have been exacerbated, but it would not have changed the qualitative dynamics. In the long run, with the inclusion of a net wealth effect, aggregate demand would still be increasing with the real interest rate ${ }^{13}$.

We thus keep a non-linear effect in the consumption specification, but without any human wealth. The real interest rate has theoretically two opposite effects on aggregate consumption in the short run if the net asset position is positive: substitution and wealth effects. Noting W the private wealth, we assume in the following that the former effect dominates the latter: private savings increases, i.e. the part of net disposable income which is devoted to the accumulation of wealth increases, and consumption decreases. In the long run however, we go back to the usual net wealth effect: wealth increases with the real interest rate and consumption is higher. Aggregate demand will hence depend negatively on the real interest rate in the short run, and positively in the long run.

To obtain this result, we use the formulation adopted by Tobin \& Buiter (1976) and according to which savings is regarded as a process which adjusts wealth towards some target value relative to income. We therefore consider that private agents form wealth plans $\tilde{W}$ which positively depend on disposable income net of wealth interests $((1-\tau) Y)$, and also on the real interest rate $(\rho)$ :

$$
\tilde{W}_{t}=\left(\alpha+\beta \rho_{t}\right)\left(1-\tau_{t}\right) Y_{t},
$$

where $\beta$ represents the sensitivity of the private wealth effect towards the real interest rate. For a zero real interest rate, the wealth over disposable income ratio is supposed to be positive ( $\alpha$ is positive).

If actual real wealth differs from planned wealth, households behaviour makes it adjust to its desired level at speed $\mu$. The demand block of the model is therefore given by a somewhat usual IS curve:

$$
Y_{t}=\left(1-\tau_{t}\right) Y_{t}+\rho_{t} W_{t}+\mu\left[W_{t}-\tilde{W}_{t}\right]+\eta\left(Y_{t}^{*}-Y_{t}\right)+\eta \varepsilon\left(\pi_{t}^{*}-\pi_{t}\right)+G_{t}+X_{t}
$$

\footnotetext{
${ }^{13}$ Suppose total wealth is the sum of physical capital, public debt and net external assets: (a); $W=K+B+F$ with (b) $K_{t}=(1-\delta) K_{t-1}+i_{t-1}(K$ : capital; $\delta$ : depreciation rate; $i$ : investment $) ;$ (c) $i_{t}=-\sigma \rho_{t}(\rho$ : real interest rate; $\sigma$. positive parameter $) ;(\mathrm{d})\left(B_{t}=\left(1-\rho_{t}\right) B_{t-1}+P D_{t}:\right.$ public debt; PD: public deficit); (e) $F_{t}=\left(1+\rho_{t}\right) F_{t-1}+T B_{t}$ (F: net external assets; $T B$ : trade balance). Incorporating eqs. (b) to (e) in eq. (a) and deriving with respect to $\rho$, one finds that wealth increases with the real interest rate as far as: (f) $B_{0}+F_{0}>\sigma$, where subscript represents initial steady state values. With values for $\sigma$ generally comprised between 0.2 and 0.3 (cf. van Aarle \& Garretsen, 2000, or van Aarle et al., 2001, for instance), it is quite easy to find initial values for public debt and the net external position which meet condition (f).
} 
Aggregate demand depends positively on disposable income gross of interests on wealth $(\rho W)$, on the gap between actual and planned wealth, on public spending $(\mathrm{G})$ and on a private demand shock $(X)$. The additional terms in output and inflation differentials reflect spillovers from the second country through the trade balance. The $\varepsilon$ parameter represents the elasticity of the trade balance to the variations of the inflation differential, it is positive; $\eta$ is the degree of openness.

Including equation (1) into (2) gives a negative effect of the real interest rate on demand in the short run if $W-\mu \beta(1-\tau) Y<0$ at the steady state, and a positive effect in the long run if $W>0$. Both conditions are met within our parametrisation.

The wealth effect introduced in the aggregate demand is close to the Pigouvian or "real balance" effect: if actual wealth is beneath its planned level, because of an increase in the real interest rate, private consumption will be reduced until savings has reached the desired equilibrium level. In the long run, households will use this savings in order to boost their own consumption.

\section{B. Aggregate Supply}

Aggregate supply is derived according to a Phillips curve with a cost effect due to the real interest rate. We assume that inputs are perfect substitutes, so that the difference between actual employment $N$ and the natural rate of employment $\bar{N}$ (the employment gap) depends on the gap between the real wage $\omega$ and the real interest rate; it further depends on the level of output:

$$
N_{t}=\bar{N}+Y_{t}-v\left(\omega_{t}-\rho_{t}\right),
$$

where $v$ is a positive parameter.

We assume that technical progress is exogenous and equal to zero. The real interest rate approximates the cost of capital, if we assume that there is no physical depreciation of capital and the price of capital is equal to unity.

The growth rate of nominal wages $S$ is indexed on the inflation rate for consumption goods and depends on the employment gap:

$$
S_{t}=(1-\eta) \pi_{t}+\eta \pi_{t}^{*}+\gamma\left(N_{t}-\bar{N}\right) .
$$

Output prices $p$ are defined according partially to a mark up and to past prices and expected inflation; we also assume that inputs are not imported:

$$
p_{t}=\lambda\left(S_{t}+\delta \rho_{t}\right)+(1-\lambda)\left(p_{t-1}+\pi_{t}^{a}\right), \text { where } 0<\lambda<1 .
$$


Using equations (3a) to (3c), we obtain the equation for inflation:

$$
\pi_{t}=\pi_{t}^{a}+\frac{\lambda}{1-\lambda}\left[\frac{\gamma}{1-L+\gamma \nu} Y_{t}+\frac{\delta(1-L)+\gamma \nu(1+\delta)}{1-L+\gamma \nu} \rho_{t}+\frac{\eta\left(\pi_{t}^{*}-\pi_{t}\right)}{1-L+\gamma \nu}\right]
$$

where $L$ is the lag operator.

We use the following simplified version of equation (3d) in our model:

$$
\pi_{t}=\pi_{t-1}+\lambda Y_{t}+(1-\theta) \rho_{t}+\eta\left(\pi_{t}^{*}-\pi_{t}\right) .
$$

Expectations are supposed to be backward-looking following some empirical controversies regarding the form of the Phillips curve ${ }^{14}$. Other arguments should mention that we concentrate on the interactions between fiscal and monetary policies only without any interference with private agents. Assuming adaptive expectations, we can neglect this fourth player while in the meantime being assured that in the long run, inflationary expectations will be met (as in Blake \& Weale, 1998). Another way to motivate the adaptive expectations assumption would be to argue that the private sector may act adaptively during the early stages of Monetary Union as they learn more about the new policy regime. At last, within our framework, stability conditions do not depend on the form of the Phillips curve, be it an expectations-augmented Phillips curve or a usual backward-looking one. Only the short-run dynamics of the inflation rate differs from one form to the other (see Leith \& Wren-Lewis, 2000).

Wealth (equation 4) is the sum of public debt and net foreign assets which grow after a trade deficit:

$$
W_{t}=B_{t}+F_{t}
$$

Equations (5) and (6) describe the dynamics of these two assets:

$$
\begin{gathered}
B_{t}=\left(1+\rho_{t}\right) B_{t-1}+G_{t}-\tau_{t} Y_{t} ; \\
F_{t}=\left(1+\rho_{t}\right) F_{t-1}+\eta\left(Y_{t}^{*}-Y_{t}\right)+\eta \varepsilon\left(\pi_{t}^{*}-\pi_{t}\right) .
\end{gathered}
$$

The model is supposed to be quarterly. Shocks occur in the first quarter of 1999 and are permanent.

\section{Governments and the $E C B$}

The two countries, named respectively 1 and 2, are engaged in a monetary union and consequently share a common currency. The common central bank (the

\footnotetext{
${ }^{14}$ See footnote 10 .
} 
$E C B)$ implements the monetary policy in the union. The rest of the world is neglected. The fiscal policy framework is asymmetric.

We implement numerical simulations in the next section and those depend extensively on the interactions of fiscal and monetary policies. Two different specifications for policies are computed. In the first one, we compute noncooperative Nash equilibrium between the three authorities ${ }^{15}$, whereas in the second, we compute cooperative Nash bargaining solutions between the three policy makers. These cooperative solutions are reached after the product of the game earnings for the three players has been maximised. Game earnings for each player are equal to the difference between the loss incurred at the Nash equilibrium and the one incurred at the cooperative equilibrium. We always verify that net earnings are positive. Policy outcomes are the result of a static game: policy makers do not anticipate that their actions will affect the future state of the economy.

In this type of model in the EMU, i.e. in the absence of any exchange rate risk, one must bear in mind that a target for public debt is (technically) needed in order to determine the division of wealth between net foreign assets and public debt. Without this target, private wealth could be balanced with unstable and symmetric levels of public debt and external assets ${ }^{16}$. In country 1 , this target is such that the government is stabilising public debt over GDP in the long run; this long term steady state level for debt is unknown in the short run. Government 1 thus controls public spending and debt with no limit in the short run. This is not the case in country 2 by assumption. In this country, the government must stabilise its debt over GDP at a pre-determined level and must do it in the short run since it has already reached the ceiling of the Stability Pact. This government must thus follow a balanced-budget rule at each period.

Goverments and the ECB minimise their loss functions at each period. For example, government 1 uses its expenditures in order to minimise its quadratic loss function each quarter (its tax rate is supposed to be constant):

$$
L G=a_{0} \Delta Y^{2}+a_{1} \Delta \pi^{2}+a_{2} \Delta(G / Y)^{2}+a_{3} \Delta(B / Y)^{2},
$$

where $\Delta$ represents the first difference operator. Government 1 is assumed to have targets for output and inflation, which are uncontroversial. Government 1 also

\footnotetext{
${ }^{15}$ When implementing its policy, each player considers the others' actions as given.

${ }^{16}$ In a flexible exchange rate regime or in the EMS, the uncertainty regarding the future value of external assets denominated in foreign currencies or the risk aversion by households are sufficient conditions for determining the discrepancy between domestic and foreign assets.
} 
incurs losses when it uses its spending: a large deviation of public expenditures from their initial level cannot be run forever; moreover, one can consider that policy-makers prefer a constant level of their instrument rather than to undertake changes all the time. In the long run, public debt has to be stabilised. More arguments than the above-mentioned one are here worth developing. First, this is in line with Leith and Wren-Lewis (2000) conclusions according to which fiscal authorities have to respond somewhat to changes in government debt. Second, via the net wealth effect, higher debt increases aggregate demand and inflation and is thus detrimental to the first two targets. Limiting the debt to GDP ratio should permit a better allocation of the fiscal instrument to output and inflation targets. Third, it also permits to include a kind of intertemporal mechanism in our static game approach: the loss function is minimised at each period, but since it incorporates debt accumulation, the government implements a trade off between satisfying its first two targets, on the one hand, and the consequences of its actions on its future rooms for maneuver (public debt as a proportion of GDP), on the other hand.

Government 2 is supposed to be fettered by the provisions of the SGP: it is able to use its tax rate $\tau$ to minimise its loss function but has to pursue meanwhile a strict balanced-budget rule. Public expenditures are used to stabilise debt, rather than tax rates, because it is well known since the seminal paper by Alesina and Perotti (1995) that fiscal adjustments are all the more efficient if expenditures are reduced. In order to analyse stabilisation and public finance issues, the loss function includes a term which captures the costs of tax collection (see Barro, 1979):

$$
\begin{gathered}
L G^{*}=a_{0} \Delta Y^{* 2}+a_{1} \Delta \pi^{* 2}+a_{2} \Delta \tau^{* 2} \\
G^{*}=(1-\chi) G_{-1}+\chi\left[\tau^{*} Y^{*}-\rho B^{*}+\mu_{g}\left(\Phi-B^{*}\right)\right]
\end{gathered}
$$

The $\Phi$ letter represents the public debt target of government 2; it is exogenous and, after being expressed in percentage of GDP, it has the same form as the public debt norm introduced in the Maastricht treaty. The $\mu_{g} \chi$ parameter represents the speed of adjustment of the public deficit to the level required to reach $\Phi$.

The introduction of two strategic equations for government 2 aims at three objectives. First, we compute Nash-bargaining equilibria and need therefore an equation of type (8); second, the cost of tax collection is not sufficient to limit fiscal policy toughly in the short run; equation (9) is more stringent; third, macro- 
economic models in the EMU usually use equation (9) as the sole strategic behavior of governments, and we found interesting to shed light on the differences between the results obtained with equation (9) with that obtained with the policy design for government 1.

The EMU is characterised by the uniqueness of the nominal short run interest rate (i) and the independence of the $E C B$. We assume that the $E C B$ sets this rate to implement its monetary policy ${ }^{17}$. We avoid the difficulties regarding the definition and level of money supply in the $E U$ and the complications due to the instability of money demand in financial economies. The $E C B$ minimises its loss function according to European average targets for output and inflation:

$$
L M=k_{0} \Delta\left(\frac{Y+Y^{*}}{2}\right)+k_{1} \Delta\left(\frac{\pi+\pi^{*}}{2}\right)^{2}+k_{2} \Delta \rho_{M}, \text { where } \rho_{M}=i-\frac{\pi+\pi^{*}}{2} .
$$

The $E C B$ has no direct target concerning the ratio of public debt over GDP since it incurs losses if the deviations of the real interest rate is large in the $E U$, i.e. if interest charges on public debts are high.

If the $E C B$ had controlled a monetary aggregate, the long term inflation rate would have been unchanged after a shock, following the so-called 'quantity theory of money'. Output would also have been unchanged. If the interest rate is determined through a reaction function, as it is now usual in macroeconomic models, the long run inflation and real interest rates are not constant, and the output level can reach a new steady state. In this situation, monetary and fiscal policies have symmetric influences on the long term inflation rate through their respective impacts on long term public debt. Both policies help to satisfy the budget constraint. This is consistent with the main conclusion of the Fiscal theory of inflation (Leeper, 1991; Woodford, 1995).

Table 1. Parameters and Intial Steady State Values

\begin{tabular}{|lccccccccc|}
\hline \multirow{2}{*}{ Parameters } & $\alpha$ & $\beta$ & $\chi$ & $\delta$ & $\lambda$ & $\eta$ & $\mu$ & $\mu_{g}$ & $\theta$ \\
& 0.3 & 2.5 & 0.85 & 0.2 & 0.25 & 0.2 & 0.3 & 0.3 & 0.05 \\
Loss functions & $a_{0}$ & $a_{1}$ & $a_{2}$ & $a_{3}$ & $a_{2}$ & $k_{0}$ & $k_{1}$ & $k_{2}$ & \\
& 0.5 & 1.5 & 0.16 & 0.5 & 0.16 & 1.5 & 3 & 0.5 & \\
Initial values & $b / y$ & $f / y$ & $w / y$ & $\rho$ & $\tau$ & $\Phi / y$ & & & \\
& 0.25 & 0 & 0.25 & 0.01 & 0.2 & 0.25 & & & \\
\hline
\end{tabular}

\footnotetext{
${ }^{17}$ There is no monetary targeting in the sense that the Central bank would set monetary aggregates at a certain level or would control that they actually reach the appropriate level. On this topic, see Svensson (1999).
} 
Macroeconomic models usually give the priority to inflation in the central bank loss function, according to the "credibility" argument: the government inflation bias needs a tough reaction by Central bankers. Although our model does not bear on such imperfections as the inflation bias, we ensure that our specifications for fiscal and monetary policies do not depart on this point from the mainstream literature. With no costs for the use of fiscal or monetary instruments, $k_{1}$ should have been superior to $k_{0}$ and $\left(k_{1} / k_{0}\right)$ should have been superior to $\left(a_{1} / a_{0}\right)$. In our formulation with costs, this latter condition can be rewritten as:

$$
\left(k_{1}-k_{2}\right) / k_{0}>a_{1} /\left(a_{0}+a_{2}-a_{3}\right)
$$

since the cost of using the interest rate reduces the capacity of the $E C B$ to curb inflation, and the cost of using the tax rate and the cost of increasing public debt reduce the capacity of governments to stabilise output. We will ensure that parameters meet this condition.

\section{Calibrations}

Since analytical solutions of the model in the face of shocks are intractable, we set the model in deviation from the steady-state and we adopted a parameter set in order to study the dynamic paths of model variables following the shocks. Our central parameter set is given in table 1 . Two considerations ${ }^{18}$ intervened in their choice: first, their realism which means either that they fit available data (the degree of openness, for example) or econometric results; second, the necessity that the model be stable.

Output is normalised at unity, and steady-state government spending is $19.7 \%$ of $G D P$, hence the amount of funds for net expenditures in the general budget of France in 1999. Initial public debt is equal to $25 \%$ of GDP and roughly corresponds to net public debt in France in 1994, thus before the cyclical (out-ofsteady-state) increase in public deficits at the beginning of the nineties had been converted in public debt. The real equilibrium interest rate is $1 \%$ and corresponds to the gap between the interest rate and the GDP growth rate in France in 1999.

Robustness of results to changing parameters is evaluated in appendix 2, although we have only focused on some important parameters: those affecting the wealth effect; the speeds of adjustment of wealth to its desired level and of public spending to the level required to reach a balanced budget; and the influence of the interest rate on inflation. We have checked that simulation results were weakly

\footnotetext{
${ }^{18}$ See the advice of Cooley (1997) on calibrated models.
} 
Table 2. Effects of a symmetric private demand shock

\begin{tabular}{|c|c|c|c|c|c|c|c|c|}
\hline & \multicolumn{4}{|c|}{ Nash equilibrium } & \multicolumn{4}{|c|}{ Coordination } \\
\hline & \multicolumn{2}{|c|}{ Ctry 1} & \multicolumn{2}{|c|}{ Ctry 2} & \multicolumn{2}{|c|}{ Ctry 1} & \multicolumn{2}{|c|}{ Ctry 2} \\
\hline & 2000 & 2010 & 2000 & 2010 & 2000 & 2010 & 2000 & 2010 \\
\hline Output (\%) & 0.118 & 0.223 & -0.128 & 0.261 & 0.230 & 0.332 & 0.048 & 0.355 \\
\hline Inflation (points) & -0.502 & -1.283 & -0.631 & -1.261 & -0.372 & -0.817 & -0.474 & -0.803 \\
\hline $\begin{array}{l}\text { Public expenditures } \\
\text { (points of } G D P \text { ) }\end{array}$ & 0.269 & 0.100 & -0.047 & -0.128 & 0.255 & 0.154 & 0.033 & -0.027 \\
\hline Tax rate (points) & 0.000 & 0.000 & -0.225 & -0.244 & 0.000 & 0.000 & -0.156 & -0.191 \\
\hline $\begin{array}{l}\text { Public debt } \\
\text { (points of } G D P \text { ) }\end{array}$ & 0.535 & 1.768 & 0.006 & 0.000 & 0.435 & 0.995 & 0.001 & 0.000 \\
\hline \multirow[t]{2}{*}{ Losses } & 0.540 & 4.059 & 0.614 & 2.427 & 0.339 & 1.555 & 0.342 & 1.035 \\
\hline & 2000 & 2010 & & & 2000 & 2010 & & \\
\hline$E C B$ 's losses & 1.214 & 5.049 & & & 0.845 & 2.358 & & \\
\hline $\begin{array}{l}\text { Real interest rate } \\
\text { (points) }\end{array}$ & -0.707 & -0.465 & & & -0.747 & -0.655 & & \\
\hline
\end{tabular}

N.B.1: results are deviations from initial values.

N.B.2: country 2 is fettered by the Stability Pact.

Table 3. Effects of an asymmetric private demand shock in country 1

\begin{tabular}{|lrrrrrrrrr|}
\hline & \multicolumn{3}{c}{ Nash equilibrium } & \multicolumn{5}{c|}{ Coordination } \\
\hline & \multicolumn{2}{c}{ Ctry 1 } & \multicolumn{2}{c}{ Ctry 2} & \multicolumn{2}{c|}{ Ctry 1 } & \multicolumn{1}{c|}{ Ctry 2 } \\
\hline & 2000 & 2010 & 2000 & 2010 & 2000 & 2010 & 2000 & 2010 \\
\hline Output (\%) & -0.149 & 0.139 & 0.088 & 0.115 & -0.086 & 0.113 & 0.130 & 0.098 \\
Inflation (points) & -0.214 & -0.651 & -0.093 & -0.667 & -0.169 & -0.339 & -0.049 & -0.349 \\
Public expenditures & 0.095 & 0.055 & 0.064 & -0.076 & 0.104 & 0.040 & -0.065 & -0.235 \\
$\quad$ points of GDP) & & & & & & & & \\
Tax rate (points) & 0.000 & 0.000 & 0.009 & -0.138 & 0.000 & 0.000 & -0.121 & -0.285 \\
Public debt & 0.773 & 0.825 & -0.003 & 0.000 & 0.757 & 1.060 & 0.006 & 0.000 \\
(points of GDP) & & & & & & & & \\
Losses & 0.380 & 0.987 & 0.017 & 0.677 & 0.334 & 0.741 & 0.014 & 0.200 \\
& $(0.42)$ & $(0.50)$ & $(0.02)$ & $(0.63)$ & $(0.35)$ & $(0.25)$ & $(0.03)$ & $(0.31)$ \\
\hline & 2000 & 2010 & & & 2000 & 2010 & & \\
\hline ECB's losses & 0.094 & 1.358 & & & 0.060 & 0.392 & & \\
$\quad(E C B$ 's losses*) & $(0.10)$ & $(0.61)$ & & & $(0.03)$ & $(0.10)$ & & \\
Real interest rate & 0.212 & -0.248 & & & -0.217 & -0.201 & & \\
(points) & & & & & & & & \\
(Real interest rate*) & $(-0.17)$ & $(-0.09)$ & & & $(-0.13)$ & $(-0.11)$ & & \\
\hline
\end{tabular}

N.B.1: results are deviations from initial values.

N.B.2: country 2 is fettered by the Stability Pact.

*: simulations with the same model, except that both countries can implement fiscal policies with no constraint in the short-medium run. Both governments have a loss function of the form given in equation (7). Only government 1 and the $E C B$ situations in our two variants can be compared since their loss functions are similar from one variant to the other. 
sensitive to the three latter parameters. As could be expected, the model is more sensitive to the $\beta$ parameter: output variations can be reversed if the wealth effect is reduced. We justify the $\beta$ value we used for our simulations in appendix 1 .

Whatever parameters values, results for the loss functions in the short, medium and long run are not substantially modified so that conclusions for the simulations still hold.

\section{Demand Shock}

The effects of negative private demand shocks of $1 \%$ of $G D P$, either symmetric or asymmetric, and reactions by the different policymakers are considered next. The shock can be characterised as an increase in the planned wealth to GDP ratio. It is a negative shock because consumption is reduced in the short run. Since countries are heterogeneous in terms of government policies, an asymmetric shock in country 1 does not give the same results as an asymmetric shock in country 2 . Above all, we are interested in the variations of the public debt over GDP ratio in country 1 since we think these have been widely ignored when establishing a fiscal asymmetry in the provisions of the Stability Pact.

\section{A. Symmetric Shock}

After a negative symmetric shock, at Nash equilibrium between the three policymakers, the nominal interest rate decreases in the $E U$ and government 1 implements an expansionary fiscal policy. Output is kept slightly over its initial steady state level and deflation is curbed (Table 2). In country 2, the tax rate, which is reduced to comply with the smoothing of fluctuations, sees its effects on output partly cancelled because public expenditures have also been decreased. The output and inflation gaps between country 1 and country 2 create an external deficit in country 1 (hence, an external surplus in country 2). The external indebtedness of country 1 will gradually dampen its output increase through the wealth effect.

In the medium run, output in country 2 is lower than in the initial steady state and the fall in the inflation rate is more pronounced than in country 1 . Since government 2 is fettered by the Stability Pact, government 1 has to implement a more expansionary policy. Note that government 1 would implement a less expansionary policy if it had to bear alone the burden of the shock (cf. Table 3). In the long run, public debt increases by 2 points of GDP in country 1 . Still, the 
Table 4. Effects of an Asymmetric Private Demand Shock in Country 2

\begin{tabular}{|lrrrrrrrr|}
\hline & \multicolumn{3}{c}{ Nash equilibrium } & \multicolumn{5}{c|}{ Coordination } \\
\hline & \multicolumn{2}{c}{ Ctry 1 } & \multicolumn{2}{c}{ Ctry 2 } & \multicolumn{2}{c|}{ Ctry 1 } & \multicolumn{2}{c|}{ Ctry 2} \\
\hline & 2000 & 2010 & 2000 & 2010 & 2000 & 2010 & 2000 & 2010 \\
\hline Output (\%) & 0.267 & 0.084 & -0.215 & 0.146 & 0.336 & 0.143 & -0.187 & 0.195 \\
Inflation (points) & -0.289 & -0.632 & -0.538 & -0.594 & -0.152 & -0.408 & -0.439 & -0.376 \\
Public expenditures & 0.175 & 0.045 & -0.111 & -0.051 & 0.169 & 0.075 & -0.061 & -0.005 \\
$\quad$ points of GDP) & & & & & & & & \\
Tax rate (points) & 0.000 & 0.000 & -0.235 & -0.106 & 0.000 & 0.000 & -0.168 & -0.086 \\
Public debt & -0.238 & 0.942 & 0.009 & 0.000 & -0.050 & 0.518 & 0.006 & 0.000 \\
(points of GDP) & & & & & & & & \\
Losses & 0.194 & 1.047 & 0.467 & 0.541 & 0.097 & 0.396 & 0.311 & 0.232 \\
& $(0.02)$ & $(0.63)$ & $(0.42)$ & $(0.50)$ & $(0.03)$ & $(0.31)$ & $(0.35)$ & $(0.25)$ \\
& 2000 & 2010 & & & 2000 & 2010 & & \\
ECB's losses & 0.637 & 1.170 & & & 0.363 & 0.556 & & \\
$(E C B$ 's losses*) & $(0.10)$ & $(0.61)$ & & & $(0.03)$ & $(0.10)$ & & \\
Real interest rate & -0.495 & -0.217 & & & -0.431 & -0.322 & & \\
$\quad$ points) & & & & & & & & \\
(Real interest rate*) & $(-0.17)$ & $(-0.09)$ & & & $(-0.13)$ & $(-0.11)$ & & \\
\hline
\end{tabular}

N.B.1: results are deviations from initial values.

N.B.2: country 2 is fettered by the Stability Pact.

*: simulations with the same model, except that both countries can implement fiscal policies with no restraint in the short-medium run.

improvement in the output in country 1 also crowds in to country 2 . The game between monetary and fiscal authorities prevent key variables (output, inflation rates) from converging to their initial steady state levels: the real long run interest rate has been decreased. However, the rise of public debt impinges on monetary policy: it has to be less expansionary in order to commit governments to more restrictive fiscal policies.

Coordinated policies, in the Nash-bargaining framework, give the following results: monetary policy in the medium and long run is more expansionary whereas fiscal policy in country 1 is less in the medium run in comparison with Nash equilibrium. Loss functions for the three policymakers are reduced and this equilibrium is Pareto-optimal. In the long run, the fall in the interest rate reduces public debt over GDP growth; to cope with the negative shock, government 1 does increase its spending more than in a Nash equilibrium. Note that policy coordination, may it be Pareto-optimal, does not mean that public spending should be lessened. 


\section{B. Asymmetric shocks}

After an asymmetric shock, the economic situation in each country not only depends on the fact that it has been hit by the shock, but also on its ability to react to it.

If the shock occurs in country 1 (Table 3 ), the relatively large use of public expenditures by government 1 at Nash equilibrium is such that the ECB is encouraged to implement a very weak expansionary policy; output falls in country 1 and its public debt soars. Country 2 is isolated from the effects of the shock in the short run since monetary policy is not tough. In the medium run, the accumulation of an external surplus in country 1 (the income and price effects on the trade balance go in the same direction) increases its external wealth and is favourable to output growth in this country. In the long run, effects of fiscal and monetary policies cancel each other: with the small reduction of the interest rate, government 1 just slightly increases its spending; there is therefore a large fall in prices which spreads over country 2 .

At the coordinated equilibrium, monetary and fiscal policies are more expansionary in the short run to keep outputs nearest to their steady state levels; this provokes a larger increase of the public debt over GDP ratio than at Nash equilibrium. In the medium run, this substantial debt provokes a strong effect on private consumption through the wealth effect and therefore leads the $E C B$ to keep its interest rate at a higher level than at Nash equilibrium; as a consequence, public spending in country 1 is dampened. Output levels in both countries are kept near to their initial levels and the fall in prices is slowed down.

If the shock occurs in country 2 (Table 4), the large price decrease in this country is such that the $E C B$ has to reduce its interest rate more toughly than in the preceding case since government 2 is unable to react to the shock. Government 1 increases its spending to compensate the deflationary shock; this can be implemented more easily than in the preceding case because public debt has dropped with interest charges. In the medium and long run, the decrease in country

Table 5. ECB's losses at Nash equilibrium*

\begin{tabular}{|c|c|c|c|c|c|c|c|c|}
\hline & \multicolumn{4}{|c|}{ Shock on country 1} & \multicolumn{4}{|c|}{ Shock on country 2} \\
\hline & \multicolumn{2}{|c|}{$\begin{array}{c}\text { Asymmetric } \\
\text { countries }\end{array}$} & \multicolumn{2}{|c|}{$\begin{array}{c}\text { Symmetric } \\
\text { countries }\end{array}$} & \multicolumn{2}{|c|}{$\begin{array}{c}\text { Asymmetric } \\
\text { countries }\end{array}$} & \multicolumn{2}{|c|}{$\begin{array}{c}\text { Symmetric } \\
\text { countries }\end{array}$} \\
\hline & 2000 & 2010 & 2000 & 2010 & 2000 & 2010 & 2000 & 2010 \\
\hline$E C B$ 's losses & 0.07 & 1.33 & 0.08 & 0.61 & 0.51 & 1.15 & 0.08 & 0.61 \\
\hline
\end{tabular}

*: losses are computed with $k_{2}=0$ in equation 10 . 
2 output will be dampened by the growth of external wealth, hence the growth of net wealth (public debt sticks to its initial level in percentage of the GDP).

In the medium run, the economic situation in country 1 , as described by government losses, is more favourable in this case than in the preceding one. Government 1 is however more involved in this shock than government 2 was when the shock occurred in country 1: government 1 losses in the present case are superior to government 2's in the preceding. In the long run, government 1 losses are superior to its own losses after the shock had hit country 1. This can be explained by the fact that the sharp fall in the real interest rate after the shock has hit country 2 has given government 1 the opportunity to implement a more and more expansionary policy in order to curb deflation. In fine, public debt has soared because the $E C B$ has decided to reduce the drop in the interest rate after public expenditures have been kept on increasing. The coordinated equilibrium does not reverse the feedback effect: the country with sound initial public finances suffers from the fiscal policy burden on its partner.

As a preliminary conclusion, coordination is always favourable for the three policymakers and it does not automatically lead to a reduction in public deficits and debts (see the case of a symmetric or asymmetric shock in country 1). We can also check that the Stability Pact places a heavy weight on government 1 and the $E C B$. In tables 3 and 4, results for the simulations of asymmetric shocks are presented in the same model as that used before except that the two countries control their fiscal instruments (they can implement whatever fiscal policy they want); hence, both countries are in the situation of country 1 in the previous model.

Country 1, whose government can implement fiscal policies in the two models, is largely burdened when government 2 is fettered by the Pact. If the shock occurs in country 2 , the loss of government 1 is divided by ten (in absolute value) if government 2 is free to choose its policy, in comparison with the situation with the Pact. Government 2 would also prefer to use its spending without restraint: macroeconomic stabilisation would not depend to a large extent on a "medium" monetary policy and the slow spillover effects of foreign policies. As for the $E C B$, its policy is always less expansionary when it does not have to substitute for a government as far as stabilisation policies in the $E U$ are concerned. Its losses are reduced. This result is not the consequence of the reduced costs for the use of the monetary instrument (see equation 10). If we do not take these costs into account, $E C B$ 's losses when both governments implement policies (countries are 
symmetric) will always be equal or inferior to losses when one of them falls under the rules of the Pact (countries are asymmetric) (Table 5).

\section{Conclusion}

Since the Amsterdam treaty in 1997, a compelling respect of the public deficit criterion has been dictated to countries willing to enter the Euroland. The so-called norm of $3 \%$ of GDP has been confirmed by the Stability Pact and will force countries either to implement pro-cyclical fiscal policies if this limit has already been reached or exceeded, or to have a very weak structural deficit in order to gain rooms for manoeuvre.

In this paper, we have dealt with the feedback effects of the Stability Pact on the $E C B$ and the country which is not directly subject to the provisions of the Pact, using a simulated two-country model. The three policymakers see their stabilisation capacities reduced by the existence of the Pact. With our dynamic and patrimonial model, we have been able to distinguish between the short-run and long-run effects of economic policies. Hence, we have shed light on the constraints falling on indebted countries. Debt implications are substantial: they change the temporal feature of monetary policy which, by way of consequence, modify fiscal policies. Note also that in this model, both countries do not have to follow fiscal balance rules. The change in fiscal policy in the long run, in order to limit debt growth in percentage of $G D P$, is a sufficient condition to reach a new steady state.

We have showed that a stringent application of the provisions of the Stability Pact may substantially fetter the framework for economic policies in the whole EU. More noteworthy, the Stability Pact impinges negatively on fiscally virtuous policymakers (countries with sound initial public finances), as well as on the $E C B$. Coordination between monetary and fiscal authorities always pays; but the $E C B$ and countries with sound public finances are likely to lose from the Stability Pact, even if policies are set under co-operation. Policy perspectives in the $E U$ may well be very dark in the case of symmetric or asymmetric shocks.

The sub-optimality of the Stability Pact for $E U$ countries will impinge also on the rest of the world, at least through the Euro exchange rate. The fact that the European nominal interest might be set at an excessive level due to coordination failures between intra-European authorities might influence the level as well as the volatility of the Euro-\$ exchange rate. As noted by some economists (see, for 
instance, Davidson, 1992-93), in an interdependent world economy, it is necessary that some degree of economic co-operation among trading partners be organized and implemented . For this purpose to be fully satisfied, in an era in which all economic spheres are interdependent, one should not add co-operation failures within trading partners.

Our future research should now be aimed at demonstrating the robustness of our conclusions within a time-consistent framework, as well as adding a "rest of the world" in order to be able to analyse the interactions between European monetary and fiscal policies and the determination of the Euro exchange rate.

\section{Acknowledgement}

I gratefully acknowledge H. Sterdyniak, E. Heyer and an anonymous referee for their helpful comments and advice. The usual disclaimer applies.

Date accepted: August 2001

\section{References}

Aarle B. (van), J.C. Engwerda, J.E.J. Plasmans and A. Weeren (2001), "Macroeconomic Policy Interaction under EMU: A Dynamic Game Approach", Open Economies Review, 12.

Aarle B. (van) and H. Garretsen (2000), "Fiscal Stabilization in the EMU", Review of International Economics, 8(4).

Alesina A. and R. Perotti (1995), "Fiscal Expansions and Adjustments in OECD Countries", Economic Policy, 21.

Alesina A. and G. Tabellini (1987), "Rules and Discretion with Non-Coordinated Monetary and Fiscal Policies", Economic Inquiry, 25.

Artis M.J. and B. Winkler (1998), "The Stability Pact: Safeguarding the Credibility of the European Central Bank", National Institute Economic Review, January.

Barro R.J. (1974), “Are Government Bonds Net Wealth ?”, Journal of Political Economy, 82, November-December.

Barro R.J. (1979), "On the Determination of the Public Debt", Journal of Political Economy, 87(5).

Barrell R. and J. Sefton (1997), "Fiscal Policy and the Maastricht Solvency Criteria", The Manchester School, 65(3), June.

Beetsma R.M.W.J. and A.L. Bovenberg (1998), "Monetary Union Without Fiscal Coordination may Discipline Policymakers", Journal of International Economics, 45, August. 
Blake A. and M. Weale (1998), "Costs of Separating Budgetary Policy From Control of Inflation: a Neglected Aspect of Central Bank Independence", Oxford Economic Papers, 50, July.

Blanchard O.J. (1985), "Debt, Deficits, and Finite Horizons", Journal of Political Economy, 93(2), April.

Blanchard O.J. (2000), Macroeconomics, second edition, Prentice Hall.

Buiter W.H. and K.N. Kletzer (1991), "Reflections on the Fiscal Implications of a Common Currency", in A. Giovannini and C. Mayer (eds.), European Financial Integration, CEPR, Cambridge University Press.

Capoen F. and P. Villa (1997), "Internal and External Policy Coordination: a Dynamic Analysis", CEPII Working Paper $n^{\circ} 97-15$, November.

Cooley T.F. (1997), "Calibrated Models", Oxford Review of Economic Policy, 13(3).

Davidson P. (1992-93), "Reforming the Worlds Money", Journal of Post-Keynesian Economics, 15(2), Winter.

Eichengreen B. (1993), "European Monetary Unification", Journal of Economic Literature, 31(3), September.

Eichengreen B. and F. Ghironi (1997), "How will Transatlantic Policy Interactions Change with the Advent of EMU?", in Eichengreen B. (ed.), European Monetary Unification, Cambridge: MIT Press.

Eichengreen B. and C. Wyplosz (1998), "The Stability Pact: More than a Minor Nuisance?", Economic Policy, 26.

European Economy (2001), "Report on the Implementation of the 2000 BEPG", Reports and Studies, 2, EC.

Fagan G., J. Henry and R. Mestre (2001), "An Area-Wide Model (AWM) for the Euro Area”, ECB Working Paper 42, January.

Fuhrer J.C. (1997), "The (Un)Importance of Forward-Looking Behavior in Price Specifications", Journal of Money, Credit, and Banking, 29(3), August.

Gali J., M. Gertler and J.D. Lopez-Salido (2001), "European Inflation Dynamics", European Economic Review, 45(7), June.

Ghezzi P. (2001), "Backward-Looking ndexation, Credibility and Inflation Persistence", Journal of International Economics, 53(1), February.

Giavazzi F. and M. Pagano (1990), "Can Severe Fiscal Contractions Be Expansionary? Tales of Two Small European Countries", in Blanchard O.J. and S. Fischer (eds.), NBER Macroeconomics Annual, The MIT Press.

Gros D. and N. Thygesen (1992), European Monetary Integration; London: Longman; NY: St Martins Press.

Hughes Hallett A.J. and D. Vines (1993), "On the Possible Costs of European Monetary Union", The Manchester School, 61(1), March.

Jensen S.E.H. and L.G. Jensen (1995), "Debt, Deficits and Transition to EMU: a Small Country Analysis", European Journal of Political Economy, 11(1), March.

Jensen S.E.H. (1997), "Wage Rigidity, Monetary Integration and Fiscal Stabilization in Europe", Review of International Economics, Special Supplement, 5(4). 
Jondeau E. and H. Le Bihan (2001), "Testing for a Forward-Looking Phillips Curve. Additional Evidence from US and European Data", Notes dEtudes et de Recherche, Banque de France, June.

Laxton D., P. Isard, H. Faruqee, E. Prasad, and B. Turtleboom (1998), "MULTIMOD Mark III. The Core Dynamic and Steady-State Models", IMF Occasional Paper 164, May.

Leeper E. (1991), "Equilibria under Active and Passive Monetary Policies", Journal of Monetary Economics, 27.

Leith C. and S. Wren-Lewis (2000), "Interactions between Monetary and Fiscal Policies", Economic Journal, 110, March.

Masson P., S. Symansky and G. Meredith (1990), "MULTIMOD Mark II: a Revised and Extended Model", IMF Occasional Paper n ${ }^{\circ} 71$, July.

Patinkin D. (1965), Money, Interest and Prices, NY: Harper and Row.

Ploeg F. (van der) (1995), "Solvency of Counter-Cyclical Policy Rules", Journal of Public Economics, 57.

Svensson L.E.O. (1999), "Monetary Policy Issues for the Eurosystem", CarnegieRochester Conference Series on Public Policy, 51, December.

Tobin J. and W.H. Buiter (1976), "Long-Run Effects of Fiscal and Monetary Policy on Aggregate Demand", in Stein J.L. (ed.), Monetarism, North Holland.

Woodford M. (1995), "Price-Level Determinacy Without Control of a Monetary Aggregate", Carnegie-Rochester Conference Series on Public Policy, 43, December.

\section{Appendix 1: Wealth effect}

Our specification for private consumption can be compared with the one used in the Multimod model of the IMF (cf. Masson et al., 1990). In this model, real private wealth $\mathrm{W}$ is the sum of human wealth, capital, money, public debt and net financial assets. The consumption function in the short run in Multimod is written:

$$
\Delta \log C=C_{0}+C_{1} \log \left(\frac{W_{-1}}{C_{-1}}\right)+C_{2} \rho+C_{3} \Delta \log [1-\tau] y+C_{4} D E M+C_{5} D U M 80
$$

where $C$ is private consumption, $D E M$ the dependency ratio which takes into account the link between young and old generations, DUM80 a dummy variable for 1980, and $\Delta$ the first difference operator. Equation (A1) has been tested with panel data for the $\mathrm{G} 7$ countries and results are: $C_{0}=-.4 ; C_{1}=.0 .9 ; C_{2}=-.59 ; \quad C=$ $.35 ; C_{4}=.19 ; C_{5}=.02$.

Consumption growth increases with wealth and disposable income's growth but 
decreases with the real interest rate. In the long run, consumption becomes:

$$
\log C=\frac{C_{0}}{0.09}+\log W-6.2 \rho+2 D E M
$$

These results do not explain much on the reasons why households want to accumulate wealth for their consumption. Moreover, is long term consumption increasing or decreasing with the interest rate? This question is unanswerable so long as wealth accumulation is not taken into account in equation (A2). This is the reason why we introduced the real wealth effect and supposed planned or desired wealth $\tilde{W}$ would be growing with the real interest rate and disposable income. Further, we considered that the propensity to save (or increase wealth) from disposable income would be growing with the real interest rate, so that we gave the priority to the following formulation:

$$
W=(\alpha+\beta \rho)(1-\tau) y
$$

For a zero real interest rate, the wealth over disposable income ratio is supposed to be positive ( $\alpha=30 \%$ ). With the initial steady state values given in table $1, \beta$ equals 2.5. In the short run, consumption in our model writes:

$$
C=(1-\tau) y+\rho W+\mu(W-\tilde{W})
$$

Wealth has two effects on consumption: households consume interests and there exist a real wealth effect. Using equations (A3) and (A4) in first difference and the initial steady state values given in table 1, private consumption reduces to:

$$
\Delta C=0.9\left(1-\tau_{0}\right) \Delta y+0.31 \rho W_{-1}-0.35 \Delta \rho
$$

This formulation differs slightly from Masson et al.'s since in our model, variations and not the level of the real interest rate impinge on consumption growth. In the long run, differences are more substantial because wealth can now be replaced by its value in equation (A3):

$$
\Delta C=\left(1-\tau_{0}\right) \Delta y+0.27 \Delta \rho
$$

Consumption growth hence depends positively on the real interest rate growth.

\section{Appendix 2: Model Robustness to Some Parameters}

We present in this section the time path of the output level at Nash equilibrium 
in the country which has been hit by the demand shock, using three different values for each parameter we study. These values meet the stability conditions of the model.

In our model, four parameters deserve peculiar attention; the two firsts are related to the private wealth effect: the sensitivity to the interest rate, $\beta$, and the speed of adjustment to the desired wealth level, $\mu$. Next, because of the introduction of a fiscal balance rule, the sensitivity of public spending to public deficit variations, $\chi$, becomes a crucial parameter. Last, inflation dynamics depends on the effect of the interest rate whose sensitivity on prices is measured by $(1+\mu)$. The different assessed values have been: $\beta=1 ; 2.5^{*} ; 4 ; \chi=0.4 ; 0.7$; $0.85^{*} ; \mu=0.2 ; 0.3^{*} ; 0.5$; and $\mu=0.025 ; 0.05^{*}, 0.2$ where a star denotes the baseline value.

A low level for the sensitivity of private wealth to the interest rate (parameter $\beta$ ) means that this wealth effect is weakened: if the negative demand shock has led to a public debt increase, the interest rate has to rise substantially (or be lessened to a smaller extent) to maintain the long run patrimonial balance. The output impact is therefore more restrictive than with larger values of $\beta$. More precisely, with a weak wealth effect, fiscal policy is very active in the short run (in comparison with a situation with a higher $\beta$ ) because public debt has no substantial effect on aggregate demand. In the medium and long run, however, this higher debt modifies monetary and fiscal policies: monetary policy, which was expansionary, and fiscal policy become very tight. The $E C B$ moves first. Afterwards, the longlasting effect on debt due to the rise in the interest rate compels the government to reduce spending. The falls in output and prices are very tough in the long run.

The parameter $\chi$ is of crucial importance as far as model stability is concerned, but it has no implication on the values of steady state variables. Small values for this parameter only slow down the time path to the new steady state.

The higher the speed of adjustment of actual to planned wealth (parameter $\mu$ ), the faster economies reach their new steady states. In the short run, a higher speed of adjustment has more substantial stabilisation effects: the gap between actual and planned wealth has more impact on aggregate demand if $\mu$ is large. Output deviations from the initial steady state are smaller. The forms of the time path between initial and final steady states are not radically changed if values of this parameter are modified.

The different values for parameter $\theta$ do not have any influence on the output steady state path. The model is therefore not sensitive to this parameter. 